\title{
Global characteristics of ambient seismic noise
}

\author{
Xiaomeng $\mathrm{Li} \cdot$ Yan Xu $\mathrm{Xu}^{\circledR}$ Chaodi Xie \\ Shanshan Sun
}

Received: 22 April 2021 / Accepted: 23 December 2021 / Published online: 17 January 2022

(C) The Author(s) 2022

\begin{abstract}
Ambient seismic noise becomes more and more important and helpful on assisting velocity model inversion, earthquake detection, and ground motion prediction. Based on the analysis of continuous seismic data and ocean wave height, we find that the ocean wave height and winter storms have a controlling factor on the DF microseismic energy level and its frequency extent in time scale. It shows that high and low DF microseismic energy accompanied with wide and narrow frequency range consistent with the high wave height period (when the ocean is stormier) and low wave height period, respectively. Since DF microseism is dominated by Rayleigh waves, its energy attenuates very quickly when it travels through shoreline to the continent crust. Our observations give a quality factor $Q$ of about 83 for DF energy traveling from the middle of the Atlantic to the central of Europe. We observe a lower energy
\end{abstract}

X. Li · Y. Xu $(\bowtie) \cdot$ C. Xie

Department of Geophysics, Yunnan University, Kunming, Yunnan 650091, People's Republic of China

e-mail: yanxu@ynu.edu.cn

\section{Li}

Wenshan Zhuang and Miao Autonomous Prefecture Water Conservancy and Electric Power Survey and Design Institute, Wenshan, Yunnan, 663000, People's Republic of China

S. Sun

Department of Atmospheric, Yunnan University, Kunming, Yunnan 650091, People's Republic of China level of SPDF (short period DF) than that of LPDF (long period DF) for the continent stations, however a reversed situation for the island stations. It suggests that short period DF energy decays faster than the long period one. High-frequency ambient noise is called microtremor. The microtremor for the island station with low elevation has a semidiurnal modulation in phase with ocean tide. The microtremor for the station at other locations are from the anthropogenic activities which have diurnal, weekly, and annually variations.

Keywords Ambient seismic noise - Microseism . Microtremor $\cdot$ Frequency-dependent polarization analysis

\section{Introduction}

With the improvement of data storage and processing technique, the signal which has been regarded as noise for a long time has been used to inverse the crust and upper mantle velocity model (Shapiro et al. 2005; Yang et al. 2010), to predict the strong grand motion (Okada 2003; Denolle et al. 2014), and to improve the earthquake detection (Zhang et al. 2010). Ambient noise has become an important dataset for seismic studies.

Ambient seismic noise at period of 2 to $20 \mathrm{~s}$ generated by the standing waves in the ocean is named microseism (Gutenberg 1958). Hasselmann (1963) 
modeled the microseism at period of 12 to $20 \mathrm{~s}$ as a nonlinear coupling between the ocean wave and the shoal or the shallow water. The energy in this period is called the primary or single-frequency microseism (SF). The theory for the microseism at period of 6 to $10 \mathrm{~s}$, called secondary or double-frequency microseism (DF), is the linear coupling between two trains of waves with the same frequency and moving toward each other (Longuet-Higgins, 1950). Noise at period around 0.5 to $2 \mathrm{~s}$ is documented as lakegenerated microseism (Lynch 1952; Peterson 1993; Koper et al. 2009; Xu et al. 2017) which might have the similar generation theory as single and double frequency microseisms. The shorter period ambient seismic noise, approximately less than $1 \mathrm{~s}$, is called microtremor mainly coming from the human activities (Gutenberg 1958; Asten 1978; Bonnefoy-Claudet et al. 2006). The frequencies of the microseism and microtremor cover the frequency band of body and surface waves.

No matter microseism or microtremor, their sources are not uniformly distributed, and their energy levels differ over the space and time. The nonuniformity of the source distribution and the difference of the energy level could bias the ambient noise tomography, earthquake location, and strong ground motion prediction.

We analyze the continuous recordings on the globally distributed IRIS/IDA (II) stations using the polarization analysis technique and examine the frequency and polarization characters of the ambient seismic noise across the globe. For microseisms, we associate with the wind speed and ocean wave height from European Centre for Medium-Range Weather Forecasts (ECMWF) to provide the relationship between the seasonal and regional variation characters of microseismic noise and ocean motion. For microtremors, we investigate their characters with respect to the station locations.

\section{Data and methodology}

IRIS/IDA (II) network includes 45 broadband stations globally (Fig. 1). In order to extract the seasonal variation of the ambient seismic noise and to avoid the temporary changes, we download 3 years of continuous data, 2016 to 2018, from IRIS Data Management Center (DMC www.iris.edu). As station ARTI has been in operation since September 2018, station TLY

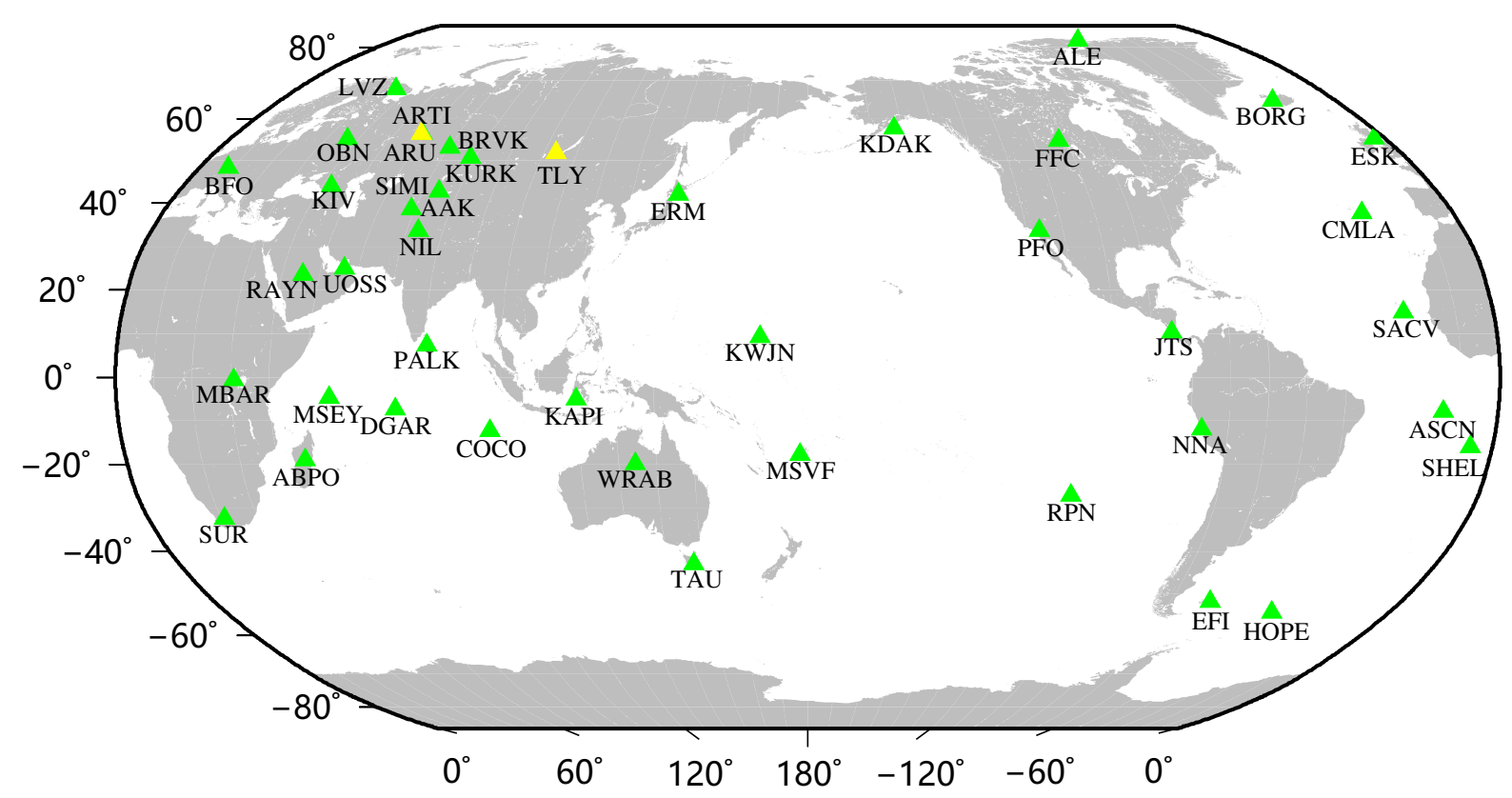

Fig. 1 Locations of 45 II stations. Green triangles are the stations used. Yellow triangles are the stations not used. XPFO has the same location as PFO. IBFO and XBFO have the same location as BFO 
was closed due to the power problems in December 2015, and IBFO, XBFO, and XPFO have another instrument at the exact same location belonging to II, these five stations are not used. Finally, three-component data (BHN, BHE, and BHZ) for 40 out of 45 stations are used in our study.

Table 1 IRIS/IDA (II) network stations used in this study

\begin{tabular}{|c|c|c|c|c|c|c|c|c|}
\hline \multirow[t]{2}{*}{ Station } & \multirow[t]{2}{*}{ Latitude } & \multirow[t]{2}{*}{ Longitude } & \multirow[t]{2}{*}{ Elevation (m) } & \multicolumn{3}{|c|}{ Used hours of data } & \multirow[t]{2}{*}{ Sampling rate } & \multirow[t]{2}{*}{ Instrument type } \\
\hline & & & & 2016 & 2017 & 2018 & & \\
\hline AAK & 42.64 & 74.49 & 1633 & 8685 & 8654 & 8679 & 40 & STS-1 V/VBB \\
\hline ABPO & -19.02 & 47.23 & 1528 & 8681 & 8627 & 8635 & 40 & STS-1 V/VBB \\
\hline ALE & 82.50 & -62.35 & 60 & 8302 & 8749 & 8743 & 40 & STS-1 V/VBB \\
\hline ARU & 56.43 & 58.56 & 250 & 8742 & 8734 & 5924 & 20 & STS-1 V/VBB \\
\hline ASCN & -7.93 & -14.36 & 173 & 8780 & 8646 & 8752 & 40 & KS-54000 \\
\hline $\mathrm{BFO}$ & 48.33 & 8.33 & 589 & 8762 & 8705 & 8733 & 20 & STS-1 V/VBB \\
\hline BORG & 64.75 & -21.33 & 110 & 8759 & 8747 & 8757 & 40 & KS-54000 \\
\hline BRVK & 53.06 & 70.28 & 330 & 8784 & 8540 & 8125 & 40 & STS-1 V/VBB \\
\hline CMLA & 37.76 & -25.52 & 429 & 8727 & 8733 & 8760 & 40 & KS-54000 \\
\hline $\mathrm{COCO}$ & -12.19 & 96.83 & 1 & 8778 & 8586 & 8702 & 40 & KS-54000 \\
\hline DGAR & -7.41 & 72.45 & 1 & 8604 & 8745 & 8760 & 40 & STS-1 V/VBB \\
\hline EFI & -51.68 & -58.06 & 110 & 8721 & 8760 & 8666 & 40 & KS-54000 \\
\hline ERM & 42.01 & 143.16 & 40 & 8649 & 8760 & 8760 & 40 & STS-1 V/VBB \\
\hline ESK & 55.32 & -3.21 & 242 & 8784 & 8760 & 8760 & 40 & STS-1 V/VBB \\
\hline FFC & 54.72 & -101.98 & 338 & 5709 & 8753 & 8748 & 40 & STS-1 V/VBB \\
\hline HOPE & -54.28 & -36.49 & 20 & 8510 & 7860 & 8743 & 40 & Trillium 240 \\
\hline JTS & 10.29 & -84.95 & 340 & 8747 & 7482 & 8261 & 40 & STS-1 V/VBB \\
\hline KAPI & -5.01 & 119.75 & 300 & 8681 & 8756 & 8645 & 40 & KS-54000 \\
\hline KDAK & 57.78 & -152.58 & 152 & 7997 & 8690 & 8738 & 40 & KS-54000 \\
\hline KIV & 43.96 & 42.69 & 1054 & 8708 & 8746 & 8756 & 40 & STS-1 V/VBB \\
\hline KURK & 50.72 & 78.62 & 184 & 8740 & 8520 & 8752 & 40 & STS-1 V/VBB \\
\hline KWJN & 9.29 & 167.54 & 0 & 0 & 3664 & 8759 & 40 & STS-5 \\
\hline LVZ & 67.90 & 34.65 & 630 & 8783 & 8752 & 8754 & 40 & STS-1 V/VBB \\
\hline MBAR & -0.60 & 30.74 & 1390 & 8784 & 8290 & 8483 & 40 & KS-54000 \\
\hline MSEY & -4.67 & 55.48 & 475 & 8722 & 8414 & 8310 & 40 & KS-54000 \\
\hline MSVF & -17.74 & 178.05 & 801.1 & 8256 & 7602 & 7204 & 40 & KS-54000 \\
\hline NIL & 33.65 & 73.27 & 629 & 4667 & 7519 & 8338 & 40 & KS-54000 \\
\hline NNA & -11.99 & -76.84 & 575 & 8784 & 8746 & 8756 & 40 & STS-1 V/VBB \\
\hline $\mathrm{OBN}$ & 55.11 & 36.57 & 160 & 8740 & 8682 & 8760 & 40 & STS-1 V/VBB \\
\hline PALK & 7.27 & 80.70 & 460 & 8780 & 7611 & 7315 & 40 & KS-54000 \\
\hline PFO & 33.61 & -116.46 & 1280 & 8756 & 8726 & 8729 & 40 & STS-1 V/VBB \\
\hline RAYN & 23.52 & 45.50 & 631 & 8739 & 5268 & 8099 & 40 & STS-2 \\
\hline RPN & -27.13 & -109.33 & 110 & 8618 & 8067 & 8706 & 40 & STS-1 V/VBB \\
\hline SACV & 14.97 & -23.61 & 387 & 8782 & 8757 & 8759 & 40 & KS-54000 \\
\hline SHEL & -15.96 & -5.75 & 537 & 8784 & 8760 & 8760 & 40 & KS-54000 \\
\hline SIMI & 38.66 & 69.01 & 1400 & 1995 & 4620 & 8661 & 40 & Trillium240 \\
\hline SUR & -32.38 & 20.81 & 1770 & 8784 & 8759 & 8758 & 40 & STS-1 V/VBB \\
\hline TAU & -42.91 & 147.32 & 132 & 8727 & 8759 & 8514 & 40 & STS-1 V/VBB \\
\hline UOSS & 24.95 & 56.20 & 284.4 & 8783 & 8699 & 8066 & 40 & STS-2.5 \\
\hline WRAB & -19.93 & 134.36 & 366 & 8773 & 8758 & 8507 & 40 & KS-54000 \\
\hline
\end{tabular}


Most of the stations are equipped with STS-1 V very broadband seismometer (Table 1). Some stations use KS-54000 ultra-low noise very broadband borehole seismometer. Few stations use Trillium 240, STS-2, or STS-5. Those broadband seismometers ensure our goal of analyzing the global characteristics of ambient noise at different frequency band. Continuous recording rate is above $80 \%$ for 37 out of 40 stations (Table 1). Since three stations, KWJN, SIMI, and NIL, with the lowest continuous recording rate can still guaranty at least a whole year of recordings, the missing data would not affect our results about seasonal variation.

We use frequency-dependent polarization analysis technique based on the eigen-decomposition of the 3-by-3 spectral covariance matrix (Koper and Hawley 2010; Park et al. 1987) to process the data. We remove the instrument response from the hour-long recordings downloaded from IRIS and restore them to ground accelerations. The hour-long data is used because transient events, e.g., small-to-moderatesized regional earthquakes, will not affect the microseism observations (Sufri, et al., 2014). We try the different length of subwindow and find that $51.2 \mathrm{~s}$ window length can provide a smooth power spectral density curve and make a full use of the data. Each hour-long data is then divided into 69 subwindows with a length of $51.2 \mathrm{~s}$ and the adjacent subwindows overlap one another by 50\%. Each subwindow is detrended and tapered with a Nuttall4c window defined with frequency limits of $0.005-0.01 \mathrm{~Hz}$ and $25-50 \mathrm{~Hz}$. Fourier transform is applied on each component in each subwindow to obtain the corresponding spectrum $y(f)$. The 3 -by-3 spectral matrix is given as

$\frac{1}{K} M^{H}(f) \cdot M(f)$

where

$$
M(f)=\left[\begin{array}{cccc}
y_{0}^{(1)}(f) & y_{0}^{(2)}(f) & y_{0}^{(3)}(f) \\
y_{1}^{(1)}(f) & y_{1}^{(2)}(f) & y_{1}^{(3)}(f) \\
\vdots & \vdots & \vdots \\
y_{K-1}^{(1)}(f) & y_{K-1}^{(2)}(f) & y_{K-1}^{(3)}(f)
\end{array}\right]
$$

where the superscripts (1), (2), and (3) of $y(f)$ represent the three components, the subscript 0 to $K-1$ indicates the number of the recordings, and $H$ means the Hermitian conjugate transpose. Eigenvalue $(\lambda)$ and corresponding eigenvector can be obtained by proceeding the eigenvalue decomposition of the spectral matrix (1). The eigenvector corresponding to the largest eigenvalue includes the polarization feature, e.g., the horizontal azimuth. For each combination of time and station, the eigenvalue can be represented as the power spectral density (PSD), power spectrogram, and probability density function (PDF).

\section{Results and discussion}

\subsection{Seasonal characters of DF microseismic energy}

We plot 3-year eigenvalues as spectrogram for all stations. Comparing ambient noise spectrograms (Fig. 2 and Fig. 3) with the ocean wave height data (Fig. 4), it is noticeable that the high wave height period in the northern or southern hemisphere has a clear controlling character on the DF microseismic energy (Stutzmann, et al., 2009; Hillers, et al. 2012).

The significant wave height in the northern hemisphere, between $30^{\circ} \mathrm{N}$ and $80^{\circ} \mathrm{N}$, from ECWMF has an obviously seasonal change, low in local summer and high in local winter (Fig. 4). The southern hemisphere has broader ocean and less land area compared with the northern hemisphere. Due to this reason, the atmospheric movement in the southern ocean is a strong and stable circulation which causes the higher wave height and relatively less seasonal changes in this ocean region than in any other ocean area (Stutzmann, et al., 2009). Even the southern ocean has the highest wave height, its wave height also has the same seasonal change, low in local summer and high in local winter, as that in the northern hemisphere.

We can tell that DF microseisms have high energy levels during local winter and low energy levels during local summer for the stations in the northern hemisphere (Fig. 2). Since ocean wave heights are high in winter and low in summer in the north Pacific and Atlantic regions (Fig. 4), the DF microseismic energy level is highly correlated with the ocean wave height on time for the northern hemisphere.

The seasons in the southern hemisphere are opposite to those in the northern hemisphere. As a result of this conversion, the DF microseismic energy also has an opposite seasonal character compared to the results from the northern hemisphere, its high energy 

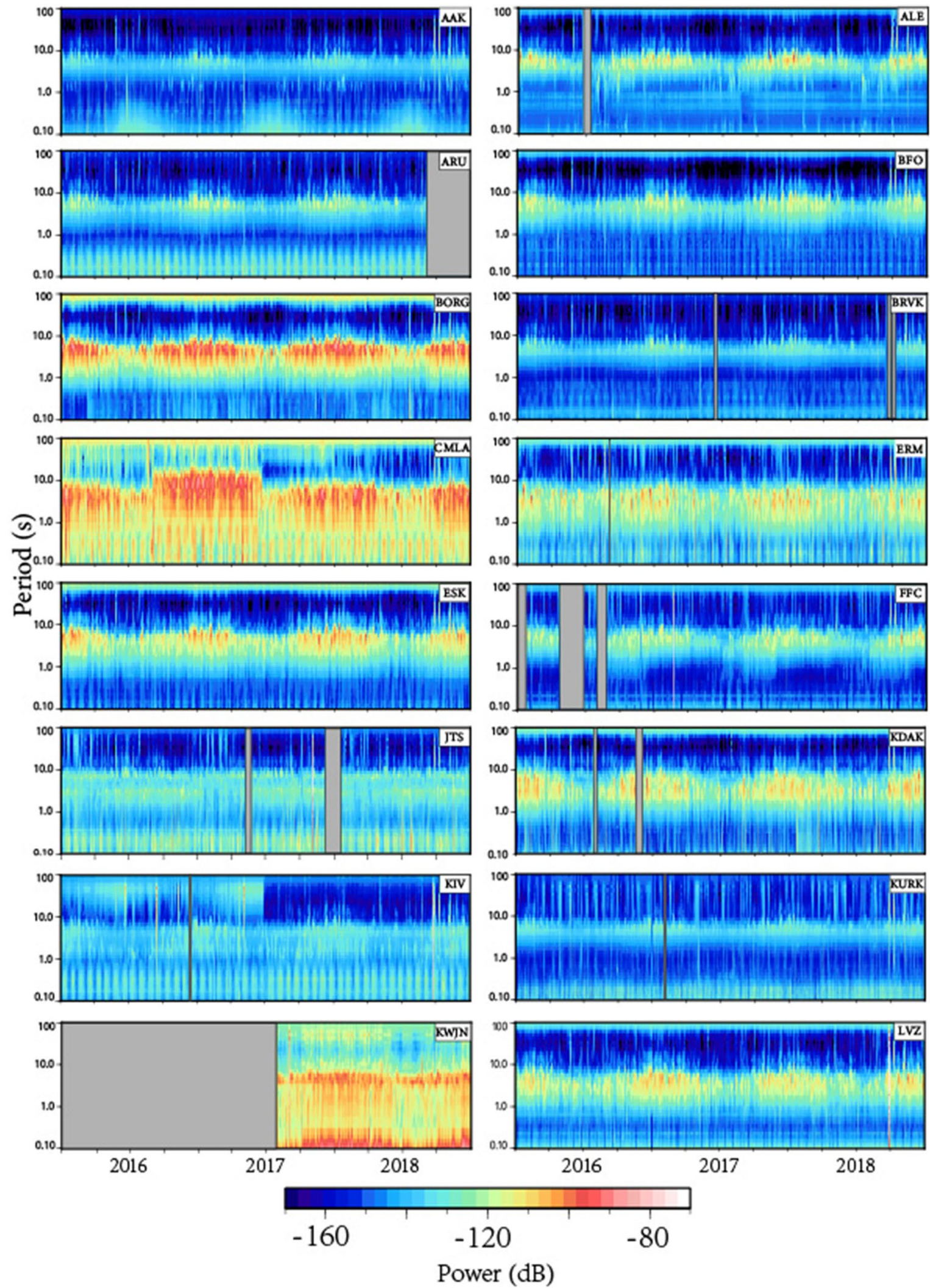

Fig. 2 Spectrograms of the eigenvalues for the stations in the northern hemisphere. Gray blocks mark the time period without data. Station name is labeled on the upper right corner 


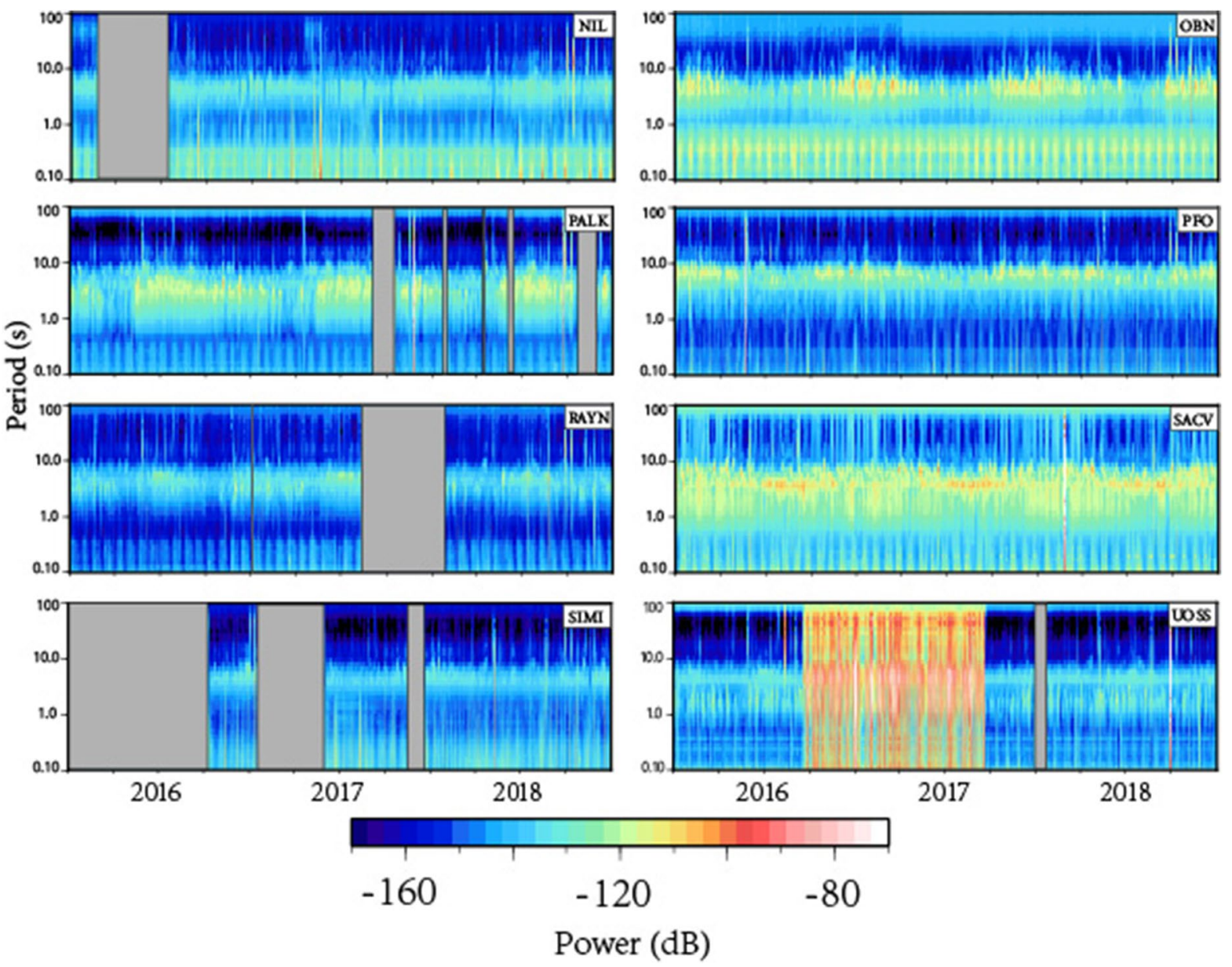

Fig. 2 (continued)

time corresponds to the high wave height time in the southern ocean from $30^{\circ} \mathrm{S}$ to $80^{\circ} \mathrm{S}$ (Fig. 4).

Combining two hemispheres, we can find that no matter the northern or southern hemisphere, seismic DF microseisms show high and low energy during local winter and local summer, respectively, which is consistent with the results of Stutzmann et al. (2000), Aster et al. (2008), and Stutzmann et al. (2009).

There are three unique stations, UOSS, RAYN, and PALK. As they locate in the northern hemisphere, we expect the high DF energy during winter and low energy level during summer. However, these stations show a reversed DF energy level, low in winter and high in summer. In Fig. 2, we plot spectrograms for all 40 stations on the same color scale in order to compare the energy levels for the different geological units. Microseismic energies of these three stations are clearly weaker than that of other stations. Besides that, since UOSS had instrument changing in between September 2016 and September 2017, its energy in this period is $30 \mathrm{~dB}$ higher than the energy in the remaining time (Fig. 2). As the character of the reverse DF energy level is not very clear using the same color scale, we replot three stations based on their own energy level in Fig. 5. Even UOSS, PALK, and RAYN locate in the northern hemisphere, DF energy shows high in summer and low in winter. UOSS and RAYN locate in the Arabian Peninsula and PALK locates in Sri Lanka, where are far away from the high wave height area in the northern hemisphere, the north Pacific and Atlantic regions, but close to the Arabian sea, northern Indian ocean. Significant wave height shows high wave during summer and low wave during winter in the Arabian sea (Fig. 4) with 
the same dynamics as in southern hemisphere. This character is also observed by Koper et al. (2009). The time of high wave height in the Arabian sea correlates with the time of high DF energy, which suggests that the nearby open water has more influence on the DF microseism energy for these three stations.

This result is reinforced by DF microseismic observations at stations near the southern ocean. Since the southern ocean has few lands, the atmospheric movement in the region is a strong and stable circulation which causes the higher wave height and relatively less seasonal changes in this ocean region than in any other ocean area. Due to this fact, some stations close to the southern ocean have high DF microseismic energy throughout the year without seasonal changes, e.g., station SUR, EFI, and HOPE in Fig. 3.

These observations refine the DF microseismic energy generation area. The DF microseismic energy comes from the nearby open water with high wave height. The north Pacific and north Atlantic control DF microseismic energies of most of stations in the northern hemisphere, showing high DF energy in winter and low energy level in summer. The Arabian sea controls DF microseismic energies of the nearby stations, which have high DF energy in summer and low in winter. The southern ocean controls DF microseismic energies of the stations in the southern hemisphere. There is no seasonal DF microseismic energy variation at stations very close to the southern ocean, but high DF energy all year long. Other stations in the southern hemisphere also have a seasonal DF microseismic energy variation, high in winter and low in summer. This correlation is consistent with the previous results, that is, the sources of the DF microseisms is related to the highest wave areas in the northern and southern hemisphere (Stutzmann et al., 2009). Besides the high wave height, the variations in microseismic power have been linked to the presence of ocean storms (Bromirski and Duennebier 2002; Barruol et al. 2006; Gerstoft and Tanimoto 2007; Stutzmann et al. 2009). The climate perturbation transfers its energy to the water column through air-sea interactions to form the standing gravity waves that propagate to the ocean floor. This transferred energy increases significantly during large oceanic storms.

In addition to the consistence between the DF microseismic energy level and the seasonal wave height, the frequency range of the microseismic energy has a fusiform shape which co-changes with the energy level and the ocean wave height, wide frequency range at its loop corresponding to the high DF energy and high wave height, and narrow frequency range at its node corresponding to the low DF energy and low wave height (Fig. 2). It might suggest that the high wave height can affect more coastal area and has more power to generate strong DF micriseismic energy at a wider frequency range. This fusiform shape of the frequency range also relates to the storms. The energies shift toward longer periods during winter is due to the longer gravity wave produced by larger winter storms (Webb 1998; Stutzmann et al. 2000; Grob et al. 2011).

\subsection{DF energy affected by the station location}

BORG in Iceland, CMLA on Sao Miguel island, KWJN on Marshall islands, DGAR on Chagos islands, and COCO on Cocos islands are all island stations, which have the same DF character, high DF energy and broad frequency extent. As island broadly exposes to swell propagating from multiple source regions, which could end in broader DF microseismic energy frequency range and high energy (Aster 2008). DF energy is mainly radiated as Rayleigh wave which attenuates very quick when it travels through shoreline to the continent crust. The quality factor $Q$ of surface waves can be expressed as $Q=\frac{\pi f}{\alpha U}$, where $f$ is frequency, $U$ is group velocity, and $\alpha$ is the attenuation coefficient. We calculated the median daily DF peak energies of five stations from the island to the interior of Europe (Fig. 6). The median DF energies of five stations have the same fusiform shape, high in winter and low in summer, and gradually attenuate as the station location moving from the island to the inland. The median DF energy drops about $35 \mathrm{~dB}$ from the station BORG on island to the station AAK on inland, separated by about $7500 \mathrm{~km}$, giving an attenuation coefficient $\alpha$ of about $0.005 \mathrm{~dB} / \mathrm{km}$. Michell (1995) provided the attenuation coefficients $\alpha$ of fundamental-mode Rayleigh waves at periods of $6 \sim 103 \mathrm{~s}$ for several study areas in the range of $0.0002 \sim 0.001 / \mathrm{km}$. Using an average Rayleigh wave group velocity of $1.25 \mathrm{~km} / \mathrm{s}$ and frequency 6 s give a quality factor $Q$ of about 83 . This low 

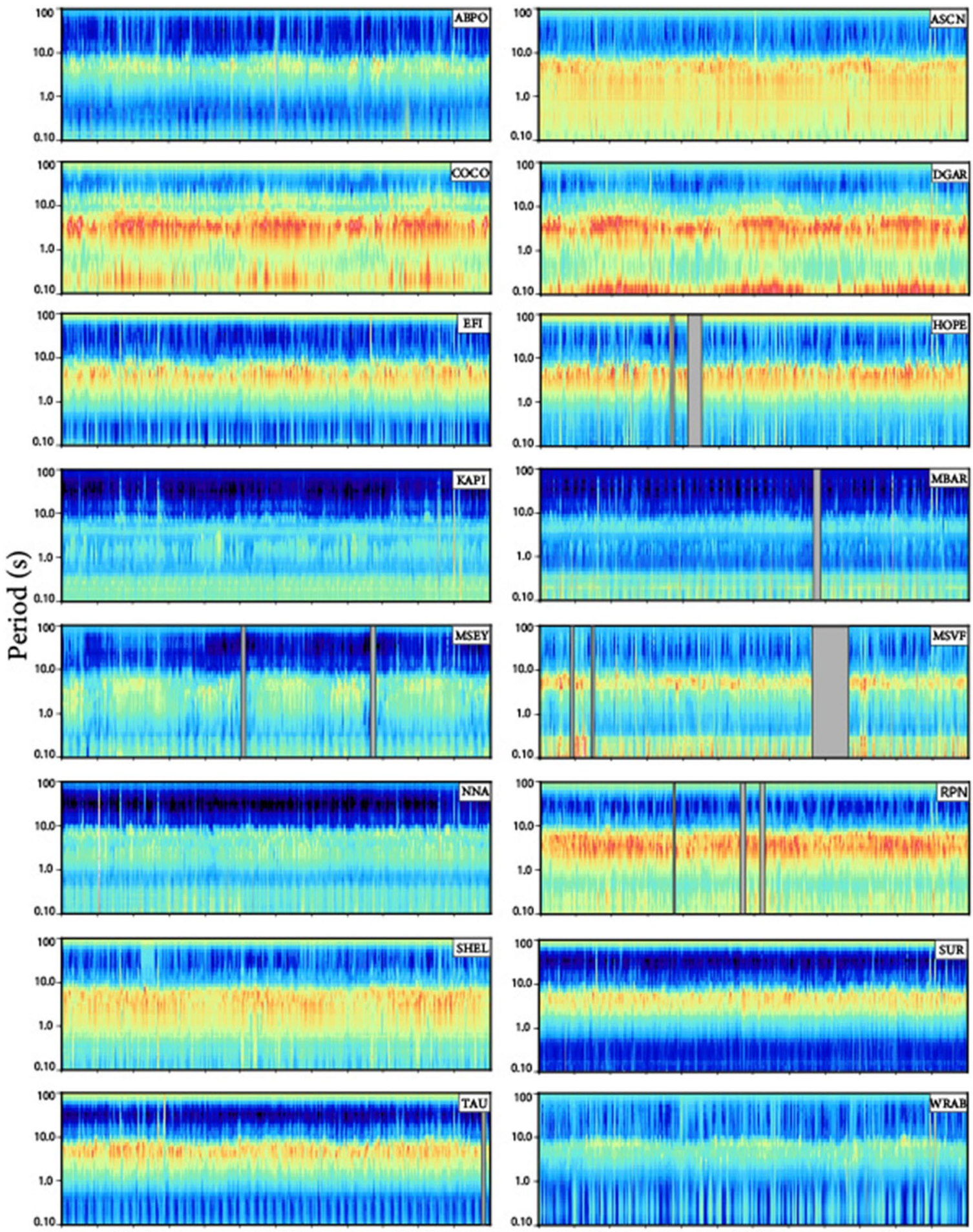

2016

2017

2018

2016 2017

2018

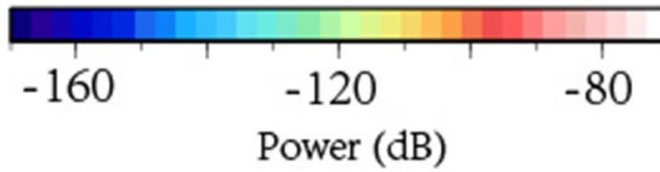


4Fig. 3 Spectrograms of the eigenvalue for the stations in the southern hemisphere. Gray blocks mark the time period without data. Station name is labeled on the upper right corner

$Q$ estimate is consistent with the study of amplitude variations of Rayleigh waves across a continental margin (McGarr, 1969) and reflects the high attenuation of DF energy along the long traveling path from the coast to the continent.

\subsection{Polarization of the DF energy}

Frequency-dependent polarization analysis technique will provide the information of spectral ground acceleration and its azimuthal orientation. The direction information can help analyze the relationship between the DF energy and the wave height. We plot the histogram of the azimuth of the peak DF energy for all stations and find that most stations have a dominant direction of DF peak energy, e.g., station ALE, ABPO, PFO, and SUR in Fig. 7. These directions do not necessarily point to the high wave height area, but to the nearby coast, which is consistent with the previous results that DF microseism is generated in the shallow water near the shoal rather than the deep ocean (Bromirski and Duennebier 2002; Bromirski et al. 1999).

Some inland stations, e.g., SIMI, KURK, and BRVK, have a wider azimuthal range. This character also happens to some island stations, ASCN, EFI, and SHEL. This wider azimuthal result informs that DF energies come from multiple sources in the surrounding oceans.

\subsection{Splitted DF peak}

Previous observations (Stephen et al. 2003; Bromirski et al. 2005, 2013) have found that DF microseism splits into two parts: LPDF (long-period DF about 0.085 to $0.2 \mathrm{~Hz}$ ) and SPDF (short-period DF about 0.2 to $0.45 \mathrm{~Hz}$ ). Not all stations can observe this splitting of the DF energy at any time. Five of our observations, JTS, KAPI, NNA, PALK, and SACV, can observe this DF energy splitting almost all year long (Figs. 2 and 8). The locations of five stations do not have a common factor, three out of five stations, KAPI, PALK, and SACV, on the island, another two stations, JTS and NNA, on the continent. Bromiski et al. (2005) suggested a strong correlation between the high wind speed and the DF amplitude. However, none of five stations closes to any major high wind speed areas (Fig. 8). Bromiski et al. (2005) also found that nearshore local wave activity is the major source for SPDF and LPDF. Since SPDF and LPDF are both mainly propagating as Rayleigh waves, and the short period energy attenuates faster than the long period one when the signals travel to the land, we can see that the SPDF energy is higher than the LPDF energy for three island stations (Fig. 8a, b, and c) and is lower than the LPDF energy for two land stations, JTS and NNA (Fig. 8e, f).

\subsection{Microtremor characters}

Noise with periods less than $1 \mathrm{~s}$ is named microtremor. Since seismic station noise levels vary with geographic location (Peterson 1993; Reif et al. 2002; Stutzmann et al. 2000; McNamara and Buland 2004), microtremor has a clearly regional character.

Ocean is one of the primary contributors to microtremor (Webb 1998; McNamara and Buland 2004). COCO, DGAR, and KWJN are all on the island with $0 \mathrm{~km}$ or $1 \mathrm{~km}$ station elevation (Table 1). The microtremors of three stations are at least $20 \mathrm{~dB}$ higher than those of other stations (Figs. 2 and 3) and appear the same characters as the DF microseism, high energy level during summer and low energy level during winter, and a half fusiform shape of frequency range co-changing with energy level. These characters suggest that microtremors at these stations are controlled by the high wave height in the north Pacific and southern ocean like the DF microseism. Especially, microtremor energy at KWJN station has a semidiurnal modulation in phase with ocean tide (Fig. 9). As we cannot find the tide observation at the KWJN station, we plot microtremor energy in between May 14 to May 202018 from KWJN station against the observed ocean tide from the nearby Apia port, Samoa. Since the tide observation is available since July 2019, we download the tide data with the same time period in 2020 instead of in 2018, from National Marine Data and Information Service, NMDIS, http:// global-tide.nmdis.org.cn/Default.html. Microtremor from KWJN station has two peaks approximately separated with $12 \mathrm{~h}$. Ocean tide also has two high tides every day and highly correlates with microtremor high energy in time. The similar semidiurnal 
Spring

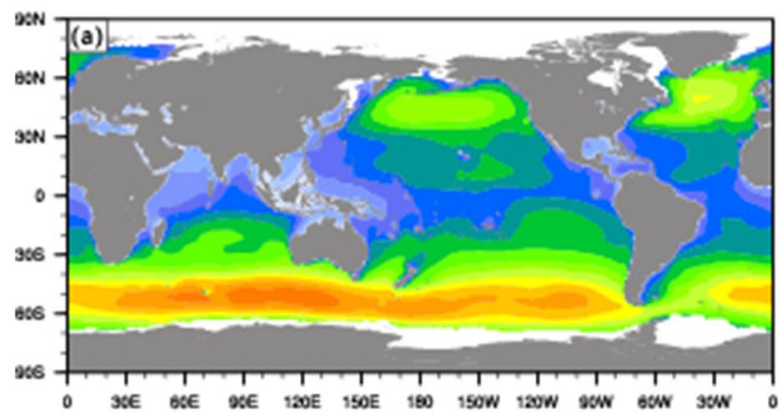

Autumn

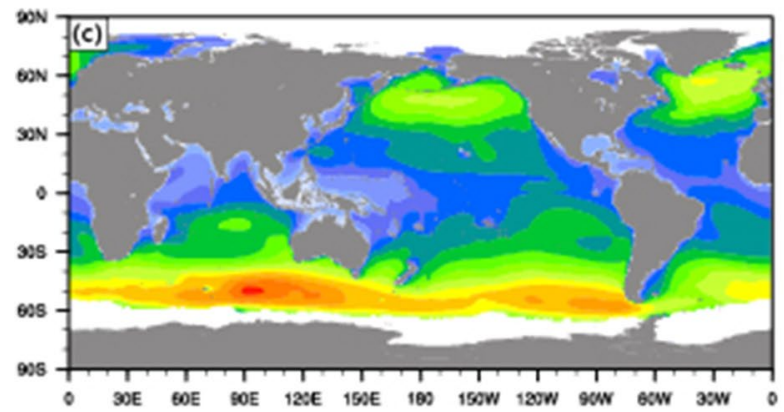

\section{Summer}

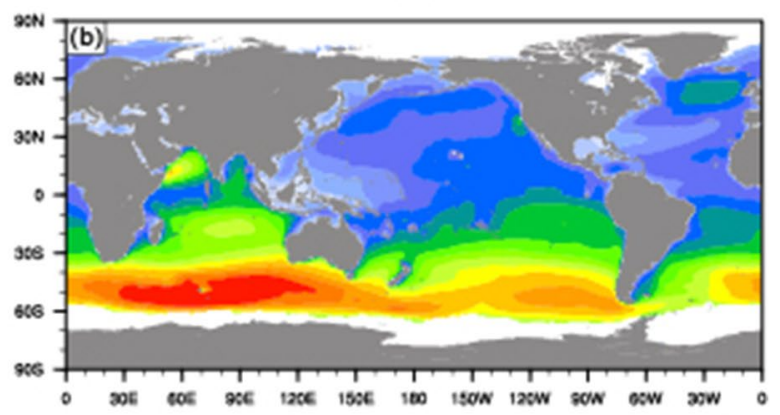

Winter

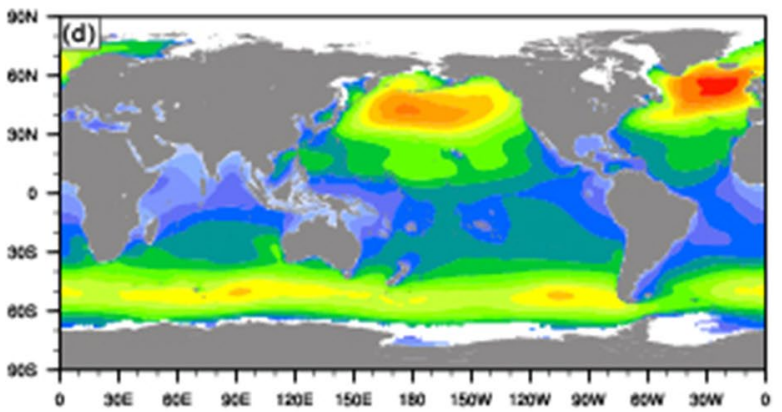

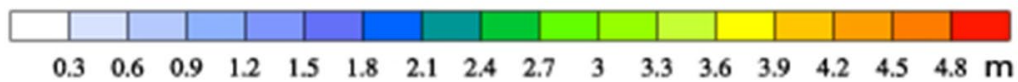

Fig. 4 Seasonal averaged significant wave height over 3 years for a spring (Mar-Apr-May), b summer (Jun-Jul-Aug), c autumn (SepOct-Nov), and d winter (Dec-Jan-Feb) from European Centre for Medium-Range Weather Forecasts (ECMWF)
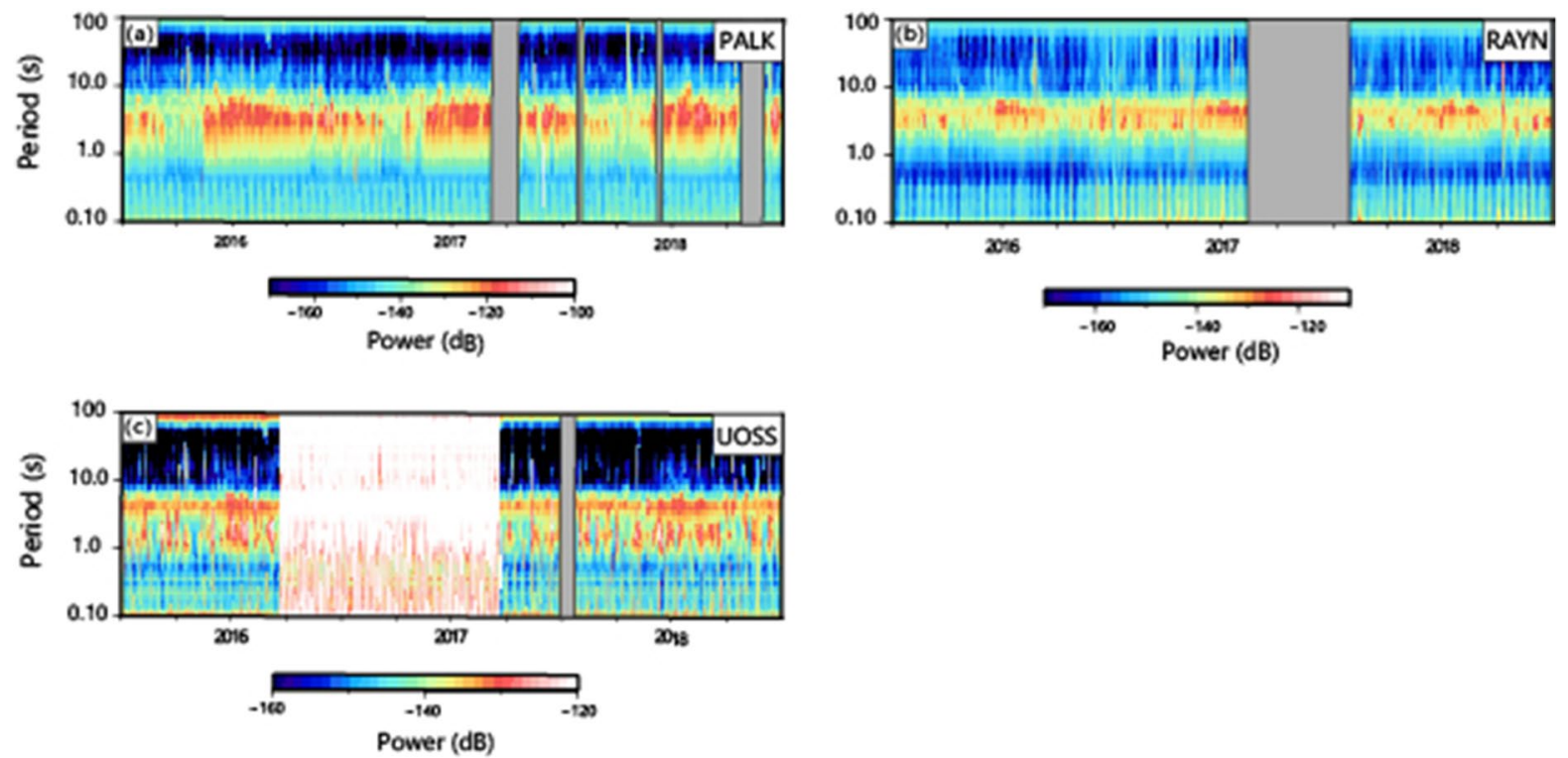

Fig. 5 Spectrograms for stations around the Arabian sea. Gray blocks mark the time without data 

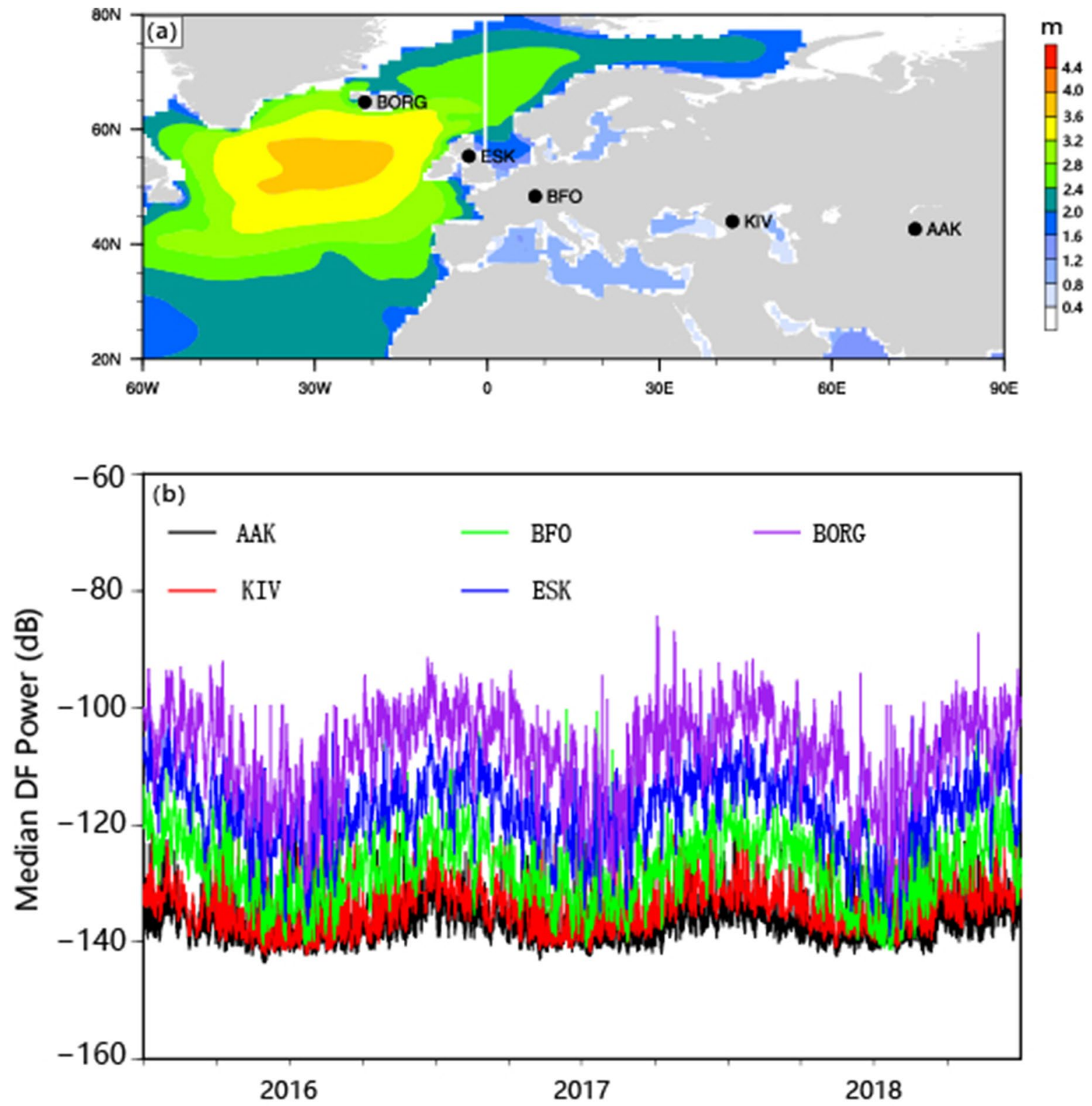

Fig. 6 a Three years mean significant wave height in the Atlantic and the locations of five seismic stations in Europe. b Median daily DF peak energies at five seismic stations

modulation in phase with tides is observed for the infragravity wave energy, which is interpreted as the result of nonlinear transfers of energy from lowfrequency long waves to higher-frequency motions, microseisms (Thomson et al. 2006; Dolenc et al. 2008). When the waves propagate over the convex low-tide beach profile than over the concave hightide profile, the observed infragravity waves have less energy at low tides (Thomson et al. 2006). Our microtremor energy having a semidiurnal modulation in phase with ocean tide shows that the similar mechanism for the infragravity waves could reach to higher frequency band. Microtremors generated by the ocean waves attenuated very quickly with increasing the elevation as this high-frequency energy propagates mainly as high-frequency surface 


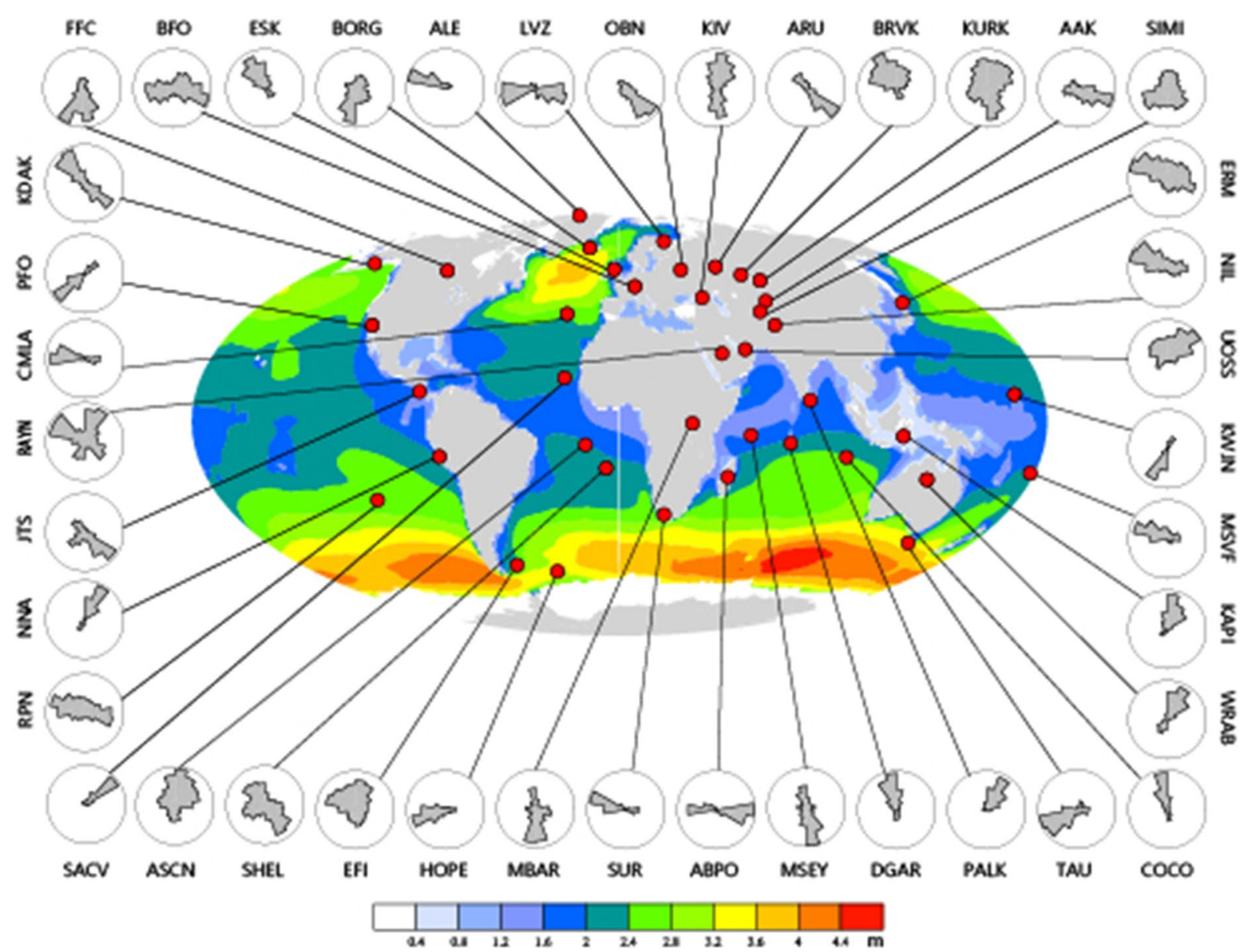

Fig. 7 Three years mean significant wave height and the distribution of back azimuths estimated for DF microseisms at 40 stations. Red dots are the location of stations

waves that attenuate within several kilometers in distance and depth (McNamara and Buland 2004). HOPE and RPN are both on island with station elevations of 40 and $110 \mathrm{~m}$, respectively. Their microtremor energies are clearly lower than that of the island stations, COCO, DGAR, and KWJN (Fig. 2).

In addition to the noise generated by the ocean, anthropogenic activities are another important source for the microtremor. Microtremors caused by the anthropogenic activities have obvious diurnal, weekly, and seasonal variations (McNamara and Buland 2004; Bonnefoy-Claudet et al. 2006; Anthony et al. 2015). For example, AAK station locates near the Ala Archa National Park in Kyrgyzstan. This national park opens all year round, with the best visiting time from the end of spring to the beginning of the autumn. Our microtremors show a very obvious seasonal change, high in summer and autumn and low in spring and winter, which is consistent with the anthropogenic seasonal characters of visiting the national park (Fig. 2). ALE station is in Alert, N. W. T, Canada, where is inside the Arctic circle with Polar day from last week of March till mid-September and Polar night from mid-December till end of February. Microtremor of ALE station is quiet during January 2018 and noisy during August 2018 (Fig. 10a,b), consistent with the Polar day and Polar night time. The clear high energies in January 2018 are associated with the earthquakes occurred globally (Fig. 10a). BFO station is in the Black Forest, Schiltach, Germany. On the 3-year scale shown in Fig. 2, it is difficult to find the diurnal and weekly characters of microtremor. Zooming into 0.11 to $0.25 \mathrm{~s}$ and only plotting 2 weeks' data, we can see a clear behavior 

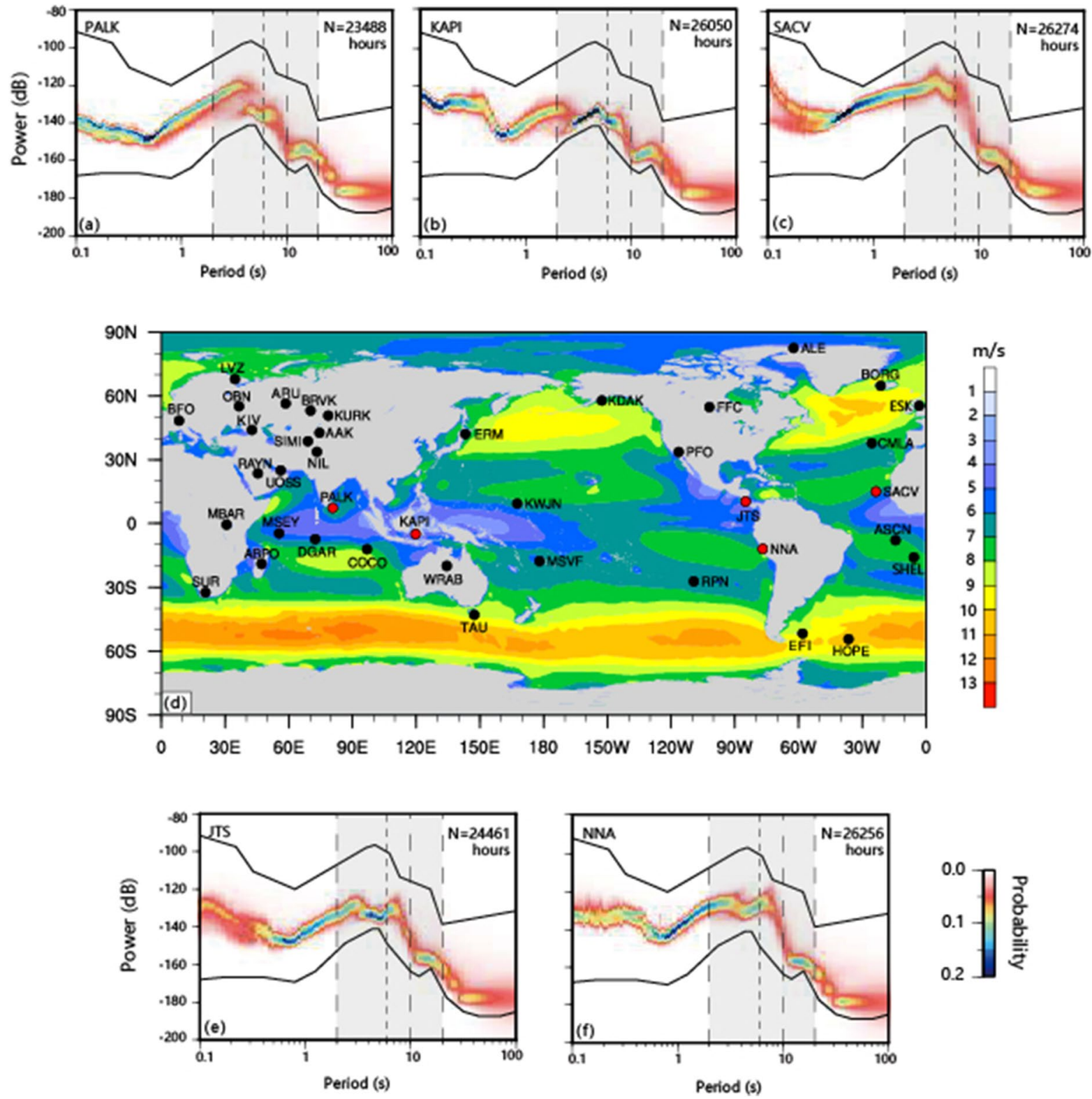

Fig. 8 Probability density functions (PDF) for ambient seismic noises of the eigenvalue for five stations, $\mathbf{a}$ is for station PALK, $\mathbf{b}$ is for station JTS, $\mathbf{c}$ is for SACV, $\mathbf{e}$ is for KAPI, and f is for NNA, from 2016 to 2018 . The black lines are the low and high reference models of Peterson (1993). Power is measured in decibel units $(\mathrm{dB})$ of spectral acceleration. $\mathbf{d}$ is 3 years median wind speed and the location of 40 seismic stations,

of the weekly anthropogenic activities near the BFO station, Fig. 10c. Monday to Friday are the work days, correspondingly high energy levels are observed in the high-frequency band. Microtremor on Saturday

black and red circles. Red circles represent the location of five stations showing PDF in (a), (b), (c), (e), and (f). The greyshaded area indicates the microseism band of 2-20 s, and the dashed vertical lines divide this into single-frequency (SF, 10-20 s) and double-frequency (DF, 2-10 s) bands. The dotted vertical line divides the DF band into short-period (SPDF, 2-6 s) and long-period (LPDF, 6-10 s) bands

morning shows some relatively weaker human movements compared to the energy level on weekdays and stops around $12 \mathrm{am}$. Microtremor reveals a quiet anthropogenic activity continuing from Saturday 
Fig. 9 Comparison of the microtremor spectrogram at station KWJN in between May 14 and May 202018 with the observed tide at the nearby Apia port in Samoya, black line, in the same time period in 2020

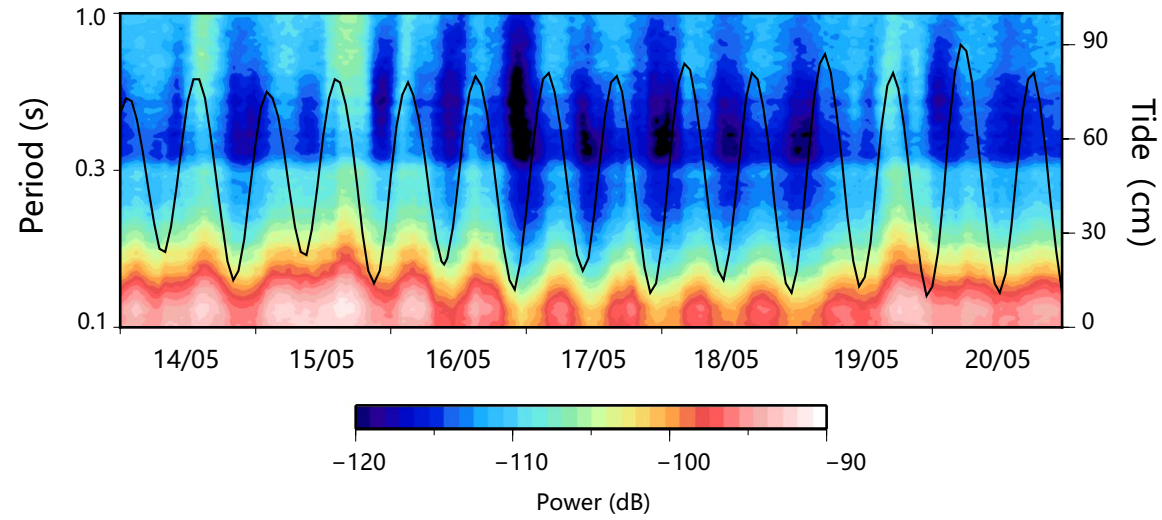

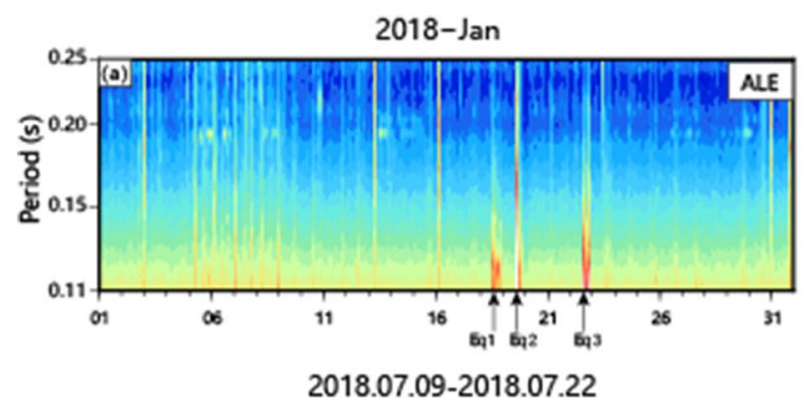

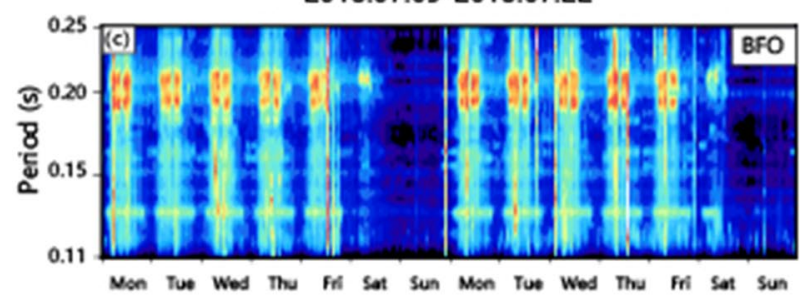

Fig. 10 The microtremor spectrogram during Polar night (January in 2018) (a) and Polar day (August in 2018) (b) at ALE station. The earthquakes larger than Mw 5.0 or Mb 5.0 occurred globally during January 2018 are marked on (a) with labels Eq. 1, Eq. 2, and Eq. 3. Equation 1: 2018-01-18

afternoon to Sunday. Except this weekly behavior of anthropogenic activities, BFO also records the diurnal anthropogenic behavior. Microtremor at about $0.2 \mathrm{~s}$ rises sharply at $5 \mathrm{am}$, appears an obvious gap at noon, and drops sharply at $5 \mathrm{pm}$. The time line of the noise level highly correlates with the working pattern.

\section{Conclusions}

By analyzing three years of data from 40 three-component long operating stations and ocean wave height,
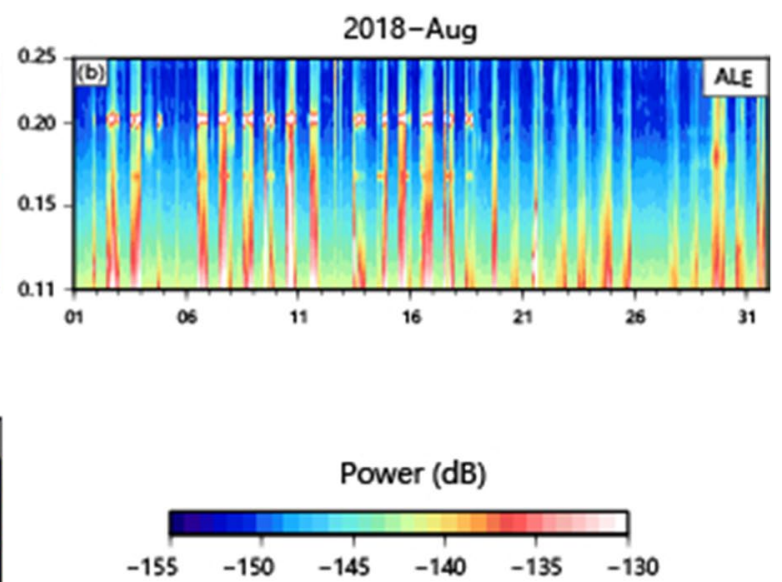

12:08:52, Northwest of Kuril Islands, Mw 5.7 and 2018-0118 17:48:39, Indonesia, Mw 5.6; Eq. 2: 2018-01-19 16:17:42, Gulf of California, Mw 6.3; Eq. 3: 2018-01-22 19:39:58, Central Mid-Atlantic Ridge, Mb 5. c Diurnal and weekly characters of microtremor at BFO station from July $9^{\text {th }}$ to $22^{\text {nd }}, 2018$

we find that DF microseismic energy level and its frequency extent mainly controlled by the ocean wave height and winter storms. Most of the stations in the northern and southern hemispheres have high energy level and wide frequency extent in winter and low energy level and narrow frequency extent in summer consistent with the high ocean wave height time in the north Pacific, north Atlantic, and the southern ocean, respectively. The time of high wave height in the Arabian sea is different from that in other oceans, which causes the DF microseismic energy of stations around the Arabian sea to be more affected by this sea area 
than by the north Pacific and north Atlantic. The station near the Arabian sea has DF low energy level and narrow frequency extent in winter which is opposite from other stations in the northern hemisphere. Due to the high wave height through the whole year in the southern ocean, the station closes to this ocean area does not have a clear seasonal variation of DF microseismic energy and frequency extent. Even the north Pacific, north Atlantic, and southern ocean control the DF energy in time scale, the direction of the peak DF microseismic energy does not point to the high wave height area but points to the nearby coast region. The polarization information suggests that the DF microseismic energy comes from the nearby coast area. As DF microseism is mainly radiated as Rayleigh wave, its energy attenuates very quick when it travels through shoreline to the continent crust. The stations from the middle of the Atlantic to the central of Eurasia plate give a quality factor $Q$ of about 83 . Owing to the same reason, short period DF energy decays faster than the long period one. We observe a lower energy level of SPDF (short period DF) than that of LPDF (long period DF) for the continent stations however a reversed situation for the island stations.

Microtremor is mainly generated by the ocean for the island station with elevation close to or equal to the sea level and attenuates pretty quick with increasing the station elevation. Anthropogenic activity is another major source of microtremor, which has diurnal, weekly, and annual variations.

Acknowledgements The authors would like to thank the anonymous reviewer and the editorial staff for their helpful comments. This work was supported by the National Science Foundation of China under awards 41564003, 41964001 and 42005122

\section{Declarations}

Conflict of interest The authors declare no competing interests.

Open Access This article is licensed under a Creative Commons Attribution 4.0 International License, which permits use, sharing, adaptation, distribution and reproduction in any medium or format, as long as you give appropriate credit to the original author(s) and the source, provide a link to the Creative Commons licence, and indicate if changes were made. The images or other third party material in this article are included in the article's Creative Commons licence, unless indicated otherwise in a credit line to the material. If material is not included in the article's Creative Commons licence and your intended use is not permitted by statutory regulation or exceeds the permitted use, you will need to obtain permission directly from the copyright holder. To view a copy of this licence, visit http://creativecommons.org/licenses/by/4.0/.

\section{References}

Anthony RE, Aster RC, Wiens D, Nyblade A, Anandakrishnan S, Huerta A et al (2015) The seismic noise environment of antarctica. Seismol. Res. Lett. 86(1):89-100. https://doi. org/10.1785/0220140109

Asten MW (1978) Geological control of the three-component spectra of Rayleigh-wave microseisms. Bull Seismol Soc Am 68(6):1623-1636

Aster CR, McNamara DE, Bromirski PD (2008) Multidecadal climate-induced variability in microseisms. Seismol Res Lett. https://doi.org/10.1785/gssrl.79.2.194

Barruol G, Reymond D, Fontaine FR, Hyvernaud O, Maurer V, Maamaatuaiahutapu K (2006) Characterizing swells in the southern Pacific from seismic and infrasonic noise analyses. Geophys J Int 164:516-542. https://doi.org/10. 11111/j.1365-246X.2006.02871.x

Bonnefoy-Claudet S, Cotton F, Bard P (2006) The nature of noise wavefield and its applications for site effects studies, A literature review. Earth Sci Rev 79:205-227. https://doi. org/10.1016/j.earscirev.2006.07.004

Bromirski PD, Duennebier FK (2002) The near-coastal microseism spectrum: spatial and temporal wave climate relationships. J. Geophys. Res. 107(B8):265. https://doi.org/ 10.1029/2001JB000265

Bromirski PD, Flick R, Graham N (1999) Ocean wave height determined from inland seismometer data: implications for investigating wave climate changes in the NE Pacific. J Geophys Res 104:20753-20766

Bromirski PD, Duennebier FK, Stephen RA (2005) Mid-ocean microseisms. Geochem Geophys Geosyst 6:Q04009. https://doi.org/10.1029/2004GC000768

Bromirski PD, Stephen RA, Gerstoft P (2013) Are deep-oceangenerated surface-wave microseisms observed on land? J Geophys Res Solid Earth 118:3610-3629. https://doi.org/ 10.1002/jgrb.50268

Denolle MA, Dunhamm EM, Prieto GA, Beroza GC (2014) Strong ground motion prediction using virtual earthquakes. Science 343:399-403

Dolenc D, Romanowicz B, McGill P, Wilcock W (2008) Observations of infragravity waves at the ocean-bottom broadband seismic stations Endeavour (KEBB) and Explorer (KXBB). Geochem Geophys Geosyst 9:Q05007. https://doi.org/10.1029/2008GC001942

Gerstoft P, Tanimoto T (2007) A year of microseisms in southern California. Geophys Res Lett 34:L20304. https://doi. org/10.1029/RG001i002p00177

Grob M, Maggi A, Stutzmann E (2011) Observations of the seasonality of the Antarctic microseismic signal, and its association to sea ice variability. Geophys Res Lett 38:L11302. https://doi.org/10.1029/2011GL047525

Gutenberg B (1958) Microseisms. Adv Geophys 5:53-92

Hillers G, Graham N, Campillo M, Kedar S, Landès A, Shapiro N (2012) Global oceanic microseism sources as seen 
by seismic arrays and predicted by wave action models. Geochem Geophys Geosyst 13:Q01021. https://doi.org/ 10.1029/2011GC003875

Koper KD, Hawley VL (2010) Frequency dependent polarization analysis of ambient seismic noise recorded at a broadband seismometer in the Central United States. Earthquake Sci 23(439-447):B10310. https://doi.org/10.1029/ 2009JB006307

Koper KD, de Foy B, Benz H (2009) Composition and variation of noise recorded at the Yellowknife Seismic Array, 1991-2007. J Geophys Res 114(B10):307

Longuet-Higgins M (1950) Theory on the origin of microseisms. Philos Trans R Soc London Ser A 243:1-35

Lynch J (1952) The Great Lakes, a source of two-second frontal microseisms. EOS Trans Am Geophys Union 33(3):432434. https://doi.org/10.1029/TR033i003p00432

McGarr A (1969) Amplitude variations of Rayleigh wavespropagation across a continental margin. Bull Seismol Soc Am 59(3):1281-1305

Mcnamara DE, Buland RP (2004) Ambient noise levels in the Continental United States. Bull Seismol Soc Am 94(4):1517-1527

Mitchell BJ (1995) Anelastic structure and evolution of the continental crust and upper mantle from seismic surface wave attenuation. Rev Geophys 33(4):441-462

Okada, H., 2003. The microtremor survey method, Geographical Monograph Series Vol. 12, Society of Exploration Geophysicists with the cooperation of Society of Exploration Geophysicists of Japan and Australian Society of Exploration Geophysicists.

Park J, Vernon FL, Lindberg CR (1987) Frequency dependent polarization analysis of high-frequency seismograms. J Geophys Res Solid Earth 92(B12):12664-12674

Peterson, J., 1993. Observation and modeling of seismic background noise (95 pp.). U.S. Geol. Surv. Open-File Rept. 93-322

Reif C, Shearer PM, Astiz L (2002) Evaluating the performance of global seismic stations. Seismol Res Lett 73(1):46-56

Shapiro NM, Campillo M, Stehly L, Ritzwoller MH (2005) High-resolution surface-wave tomography from ambient seismic noise. Science 307(5715):1615-1618. https://doi. org/10.1126/science.1108339

Stephen RA, Speiss FN, Collins JA, Hildebrand JA, Orcutt JA, Peal KR, Vernon FL, Wooding FB (2003) Ocean seismic network pilot experiment. Geochem Geophys Geosyst 4(10):1092. https://doi.org/10.1029/2002GC000485

Stutzmann E, Roult G, Astiz L (2000) Geoscope station noise level. Bull Seismol Soc Am 90:690-701. https://doi.org/ 10.1785/0119990025

Stutzmann E, Schimmel M, Patau G, Maggi A (2009) Global climate imprint on seismic noise. Geochem Geophys Geosyst 10:Q11004. https://doi.org/10.1029/2009GC002619

Sufri O, Koper KD, Burlacu R, de Foy B (2014) Microseisms from Superstorm Sandy. Earth Planet Sci Lett 402:324-336

Thomson J, Elgar S, Raubenheimer B, Herbers THC, Guza RT (2006) Tidal modulation of infragravity waves via nonlinear energy losses in the surfzone. Geophys Res Lett 33:L05601. https://doi.org/10.1029/2005GL025514

Webb SC (1998) Broadband seismology and noise under the ocean. Rev Geophys 36:105-142

$\mathrm{Xu}$ Y, Koper KD, Burlacu R (2017) Lakes as a source of shortperiod (0.5-2 s) microseisms. J. Geophys. Res. Solid Earth 122:8241. https://doi.org/10.1002/2017JB014808

Yang Y, Zheng Y, Chen J, Zhou S, Celyan S et al (2010) Rayleigh wave phase velocity maps of Tibet and the surrounding regions from ambient seismic noise tomography: Rayleigh wave phase velocities in Tibet. Geochem. Geophys. Geosyst. 11(8):119. https://doi.org/10.1029/2010GC0031 19

Zhang J, Gerstoft P, Shearer PM (2010) Resolving P-wave travel-time anomalies using seismic array observations of oceanic storms. Earth and Planet Sci Lett. https://doi.org/ 10.1016/j.eps1.2010.02.014

Publisher's note Springer Nature remains neutral with regard to jurisdictional claims in published maps and institutional affiliations. 